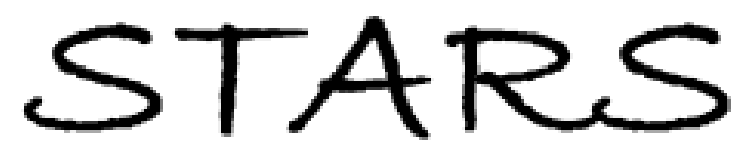

University of Central Florida

STARS

$1-1-2000$

\title{
Low temperature, postgrowth self-doping of CdTe single crystals due to controlled deviation from stoichiometry
}

\author{
V. Lyahovitskaya \\ L. Chernyak \\ University of Central Florida \\ J. Greenberg \\ L. Kaplan \\ David Cahen
}

Find similar works at: https://stars.library.ucf.edu/facultybib2000

University of Central Florida Libraries http://library.ucf.edu

This Article is brought to you for free and open access by the Faculty Bibliography at STARS. It has been accepted for inclusion in Faculty Bibliography 2000s by an authorized administrator of STARS. For more information, please contactSTARS@ucf.edu.

\section{Recommended Citation}

Lyahovitskaya, V.; Chernyak, L.; Greenberg, J.; Kaplan, L.; and Cahen, David, "Low temperature, postgrowth self-doping of CdTe single crystals due to controlled deviation from stoichiometry" (2000). Faculty Bibliography 2000s. 2682.

https://stars.library.ucf.edu/facultybib2000/2682

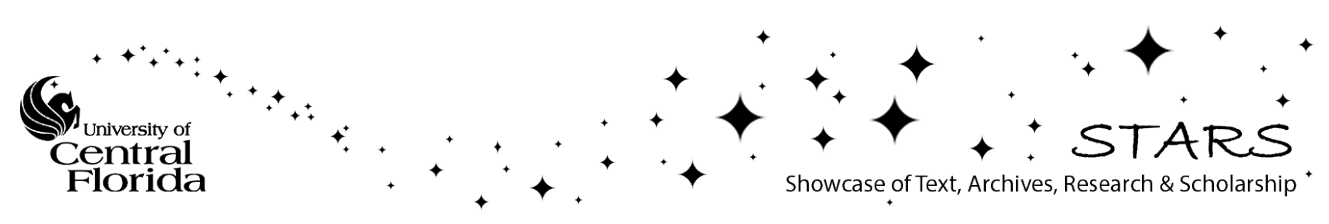




\section{Low temperature, postgrowth self-doping of CdTe single crystals due to controlled deviation from stoichiometry}

Cite as: Journal of Applied Physics 88, 3976 (2000); https://doi.org/10.1063/1.1308065

Submitted: 15 March 2000 . Accepted: 11 July 2000 . Published Online: 19 September 2000

V. Lyahovitskaya, L. Chernyak, J. Greenberg, L. Kaplan, and David Cahen

\section{ARTICLES YOU MAY BE INTERESTED IN}

Influence of oxygen stoichiometry on the electronic properties of $\mathrm{La}_{4} \mathrm{Ni}_{3} \mathrm{O}_{10 \pm \delta}$

Journal of Applied Physics 88, 544 (2000); https://doi.org/10.1063/1.373693

Annealing conditions for intrinsic CdTe

Applied Physics Letters 74, 552 (1999); https://doi.org/10.1063/1.123142

Effect of thermal annealing on Te precipitates in CdTe wafers studied by Raman scattering and cathodoluminescence

Journal of Applied Physics 77, 2806 (1995); https://doi.org/10.1063/1.358687

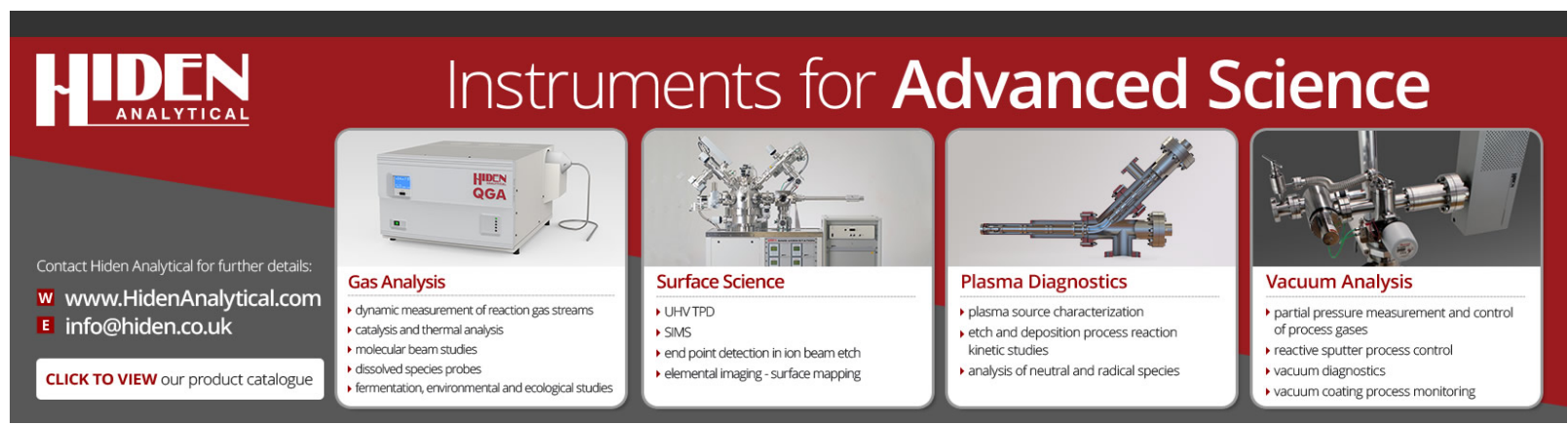




\title{
Low temperature, postgrowth self-doping of CdTe single crystals due to controlled deviation from stoichiometry
}

\author{
V. Lyahovitskaya ${ }^{\text {a) }}$ \\ Department of Materials and Interfaces, Weizmann Institute of Science, Rehovoth 76100, Israel \\ L. Chernyak ${ }^{\text {b) }}$ \\ Department of Physics, University of Central Florida, Orlando, Florida 32816 \\ J. Greenberg \\ Department of Inorganic and Analytical Chemistry, Hebrew University of Jerusalem, \\ Jerusalem 91904, Israel \\ L. Kaplan and David Cahen \\ Department of Materials and Interfaces, Weizmann Institute of Science, Rehovoth 76100, Israel
}

(Received 15 March 2000; accepted for publication 11 July 2000)

Careful analysis of the $\mathrm{Cd}-\mathrm{Te}$ pressure-temperature-composition phase diagram, shows a deviation of CdTe stoichiometry only in the Te-depletion direction between 450 and $550{ }^{\circ} \mathrm{C}$. Combined control over the semiconductor composition, via intrinsic defects, and over the atmosphere and cooling rate can, therefore, yield a process for intrinsic doping of $\mathrm{CdTe}$ at these relatively low temperatures. We present results that support this. Quenching of CdTe, following its annealing in Te atmosphere at $400-550^{\circ} \mathrm{C}$, leads to $p$-type conductivity with a hole concentration of $\sim 2$ $\times 10^{16} \mathrm{~cm}^{-3}$. Slow cooling of the samples, after $550{ }^{\circ} \mathrm{C}$ annealing in $\mathrm{Te}$ or in vacuum, increases the hole concentration by one order of magnitude, as compared to quenching at the same temperature. We explain this increase by the defect reaction between Te vacancies and Te interstitials. Annealing in $\mathrm{Cd}$ at $400-550{ }^{\circ} \mathrm{C}$ leads to $n$-type conductivity with an electron concentration of $\sim 2 \times 10^{16}$ $\mathrm{cm}^{-3}$. Annealing at $450-550^{\circ} \mathrm{C}$ in the equilibrium atmosphere, provided by adding $\mathrm{CdTe}$ powder, gives $n$-type material. (C) 2000 American Institute of Physics. [S0021-8979(00)05120-3]

\section{INTRODUCTION}

The effective use of CdTe in optoelectronics is limited by the availability of low resistive $n$ - and $p$-type material. Most doping experiments, reported up until now, were carried out with extrinsic dopants. ${ }^{1-5}$ Indium is one of the most extensively studied $n$-type dopants in CdTe. ${ }^{1,2}$ Copper, nitrogen, as well as group V elements, such as arsenic and phosphorus have been tried as acceptors. ${ }^{3,4}$ In polycrystalline thin films of CdTe of the type used in efficient solar cells (up to $16 \%$ efficiency), ${ }^{5}$ the dopant that leads to their $p$-type conductivity is not clear. As is the case with other II-VI materials, self-compensation presents a major difficulty in CdTe. ${ }^{6,7}$

From earlier work on intrinsic CdTe doping, one can conclude that it is relatively easy to get $n$-CdTe by annealing in $\mathrm{Cd}$ atmosphere over a wide temperature range, ${ }^{8}$ while making $p$-CdTe is more complex. Some results are available on annealing in a Te atmosphere to get $p-\mathrm{CdTe}^{9-12}$ and these relate to temperatures $\gtrsim 600{ }^{\circ} \mathrm{C}$. Low resistivity $p$-CdTe has been obtained by heating with $\mathrm{H}_{3} \mathrm{PO}_{4}$ (at $550{ }^{\circ} \mathrm{C}$ ) for $\sim 10$ days, followed by $\mathrm{Te}$ annealing at $400{ }^{\circ} \mathrm{C}^{3}$

It is difficult to interpret the results on intrinsic doping of $\mathrm{CdTe}$, as reported hitherto, because of an apparent lack of systematic variation of annealing temperature and cooling

\footnotetext{
${ }^{a)}$ Electronic mail: vera.lyahovitsky@weizmann.ac.il

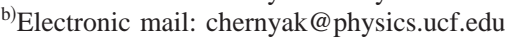

conditions. Here we summarize our results of such experiments and suggest a simple model to explain them. We found that controlled annealing at relatively low temperatures, from 400 to $550{ }^{\circ} \mathrm{C}$, suffices to tailor the electrical properties of CdTe single crystals, due to the shift of balance between native donors and acceptors. ${ }^{13,14}$ This is important for practical reasons (compatibility with other processing steps) and because it has been suggested ${ }^{7,13}$ that the tendency to self-compensation in this temperature region is lower than, say, at $\gtrsim 600{ }^{\circ} \mathrm{C}$. The latter has been explained by lower native defect densities at the lower temperatures.

\section{EXPERIMENTAL DETAILS}

Experiments were carried out on CdTe single crystals obtained from Harrick Scientific Corporation (HSC), Nippon Mining Company and the Israel Institute of Technology (Technion). Where possible, the crystals were cleaved along $\{110\}$. If this was not possible, then at least one of the randomly oriented surfaces was polished with $\mathrm{Al}_{2} \mathrm{O}_{3}$ powder, down to $0.05 \mu \mathrm{m}$ in size, and etched with $4 \% \mathrm{Br}_{2}$ in methanol solution $(v / v)$. In this way samples with faces having areas up to $1 \mathrm{~cm}^{2}$ and $1-1.5 \mathrm{~mm}$ thick were obtained. Before annealing all samples showed electrical resistivities of more than $5 \mathrm{M} \Omega \mathrm{cm}$. Their electrical conductivity type, before doping, was determined using surface photovoltage spectroscopy. ${ }^{15}$ The HSC and Technion crystals were found to be $n$ type and the NMC crystals $p$ type. After annealing resistivity measurements were performed using the four 
TABLE I. Electrical properties of CdTe annealed at 400 and $550{ }^{\circ} \mathrm{C}$ after quenching or slow cooling.

\begin{tabular}{|c|c|c|c|c|c|c|c|}
\hline \multicolumn{2}{|c|}{$\begin{array}{c}\text { Atmosphere } \\
\text { Temperature } \\
\left({ }^{\circ} \mathrm{C}\right)\end{array}$} & \multicolumn{2}{|c|}{$\begin{array}{l}\text { Annealing } \\
\text { time (days) and } \\
\text { Quenching or } \\
\text { Slow cooling }\end{array}$} & \multicolumn{2}{|c|}{$\begin{array}{l}\text { Majority } \\
\text { carrier density } \\
\left(\mathrm{cm}^{-3}\right)^{\mathrm{a}} \\
\text { cf. Fig. } 3\end{array}$} & \multirow{2}{*}{$\begin{array}{c}\begin{array}{c}\text { Mobility }^{\mathrm{a}} \\
\left(\mathrm{cm}^{2} / \mathrm{V} \mathrm{s}\right)\end{array} \\
\mu=\sigma /(\mathbf{q} \cdot \mathbf{n} \text { or } \mathbf{q} \cdot \mathbf{p})\end{array}$} & \multirow{2}{*}{$\begin{array}{r}\text { Specific } \\
\text { resistivity } \\
(\Omega \mathrm{cm})^{\mathrm{a}}\end{array}$} \\
\hline $\mathrm{CdTe}$ & 400 & 8 & $\mathbf{Q}$ & Intrinsic & $\mathbf{A}^{\mathrm{b}}$ & & \\
\hline CdTe & 550 & 4 & $\mathbf{Q}$ & $n=2 \times 10^{16}$ & B & 500 & 0.6 \\
\hline $\mathrm{CdTe}$ & 400 & 8 & $\mathbf{S}$ & Intrinsic & $\mathbf{A}$ & $\ldots$ & $5 \times 10^{6}$ \\
\hline $\mathrm{CdTe}$ & 550 & 4 & $\mathbf{S}$ & $n=2 \times 10^{16}$ & B & 500 & 0.6 \\
\hline $\mathrm{Cd}$ & 400 & 7 & $\mathbf{Q}$ & $n=3.5 \times 10^{16}$ & C & 300 & 0.5 \\
\hline $\mathrm{Cd}$ & 550 & 5 & $\mathbf{Q}$ & $n=5 \times 10^{16}$ & D & 650 & 0.2 \\
\hline $\mathrm{Cd}$ & 400 & 7 & $\mathbf{S}$ & $n=2 \times 10^{14}$ & $\mathbf{E}$ & 600 & 50 \\
\hline $\mathrm{Cd}$ & 550 & 5 & $\mathbf{S}$ & $n=1.3 \times 10^{16}$ & $\mathbf{F}$ & 470 & 1.0 \\
\hline $\mathrm{Te}$ & 400 & 7 & $\mathbf{Q}$ & $p=2 \times 10^{16}$ & $\mathbf{K}$ & 55 & 6 \\
\hline $\mathrm{Te}$ & 550 & 5 & $\mathbf{Q}$ & $p=1.5 \times 10^{16}$ & $\mathbf{L}$ & 2.5 & 190 \\
\hline $\mathrm{Te}$ & 440 & 7 & $\mathbf{S}$ & Intrinsic & $\mathbf{A}$ & $\ldots$ & $2 \times 10^{6}$ \\
\hline $\mathrm{Te}$ & 550 & 5 & $\mathbf{S}$ & $p=2 \times 10^{17}$ & M & 5 & 67 \\
\hline Vacuum & 400 & 7 & $\mathbf{Q}$ & $p=1 \times 10^{16}$ & $\mathbf{K}$ & 70 & 10 \\
\hline Vacuum & 550 & 5 & $\mathbf{Q}$ & Intrinsic & $\mathbf{O}$ & $\cdots$ & $2 \times 10^{6}$ \\
\hline Vacuum & 400 & 7 & $\mathbf{S}$ & $p=1 \times 10^{15}$ & $\mathbf{N}$ & 60 & 110 \\
\hline Vacuum & 550 & 5 & $\mathbf{S}$ & $p=6.5 \times 10^{17}$ & $\mathbf{M}$ & 35 & 0.3 \\
\hline
\end{tabular}

${ }^{a}$ The numbers are the averages of all valid measurements, as detailed in the experimental section.

${ }^{\mathrm{b}} \mathbf{A}-\mathbf{O}$ refer to the points on the T-X diagrams given in Fig. 3, to describe the different CdTe compositions achieved after annealing.

point Van der Pauw configuration and Hall mobility measurements were made with this configuration in a magnetic field of $0.5-2 \mathrm{~T}$ and then calculated from these results. Carrier concentrations and mobilities, as well as the electrical conductivity type after annealing were determined from these measurements. Six runs of Hall measurements were performed on each sample under investigation and the average values of resistivity, mobility and carrier concentrations were found. Mostly three samples (one from each source) were used in every set of annealing experiments. In total the data are based on the results from $2(\mathrm{Cd}), 5$ (Te and vacuum) and 7 (CdTe) sets. The results, presented in Table I, are on the experiment level, i.e., they were obtained by averaging the results obtained on the sample level. The maximum standard deviation for the electrical parameters within a single and between different experiments did not exceed 20\%. The fact that Hall measurements on crystals from several sources, but annealed under the same conditions, gave similar results, indicates that the role of foreign impurities or growthinduced defects in the observed changes of the electrical conductivity type is minor.

Ohmic contacts to $n$-CdTe, required for their electrical measurements, were made using a Ga:In $(1: 3 w / w)$ eutectic. Contacts to $p$-type crystals were made by chemical deposition of $\mathrm{Au}$ from gold chloride solution. ${ }^{16}$

Annealing of CdTe crystals was carried out in 12-14cm-long quartz ampoules with a 10-12 mm inner diameter. The samples were spatially separated, by a thin neck, $\sim 2$ $\mathrm{mm}$ in diameter, from elemental $\mathrm{Cd}$, from elemental $\mathrm{Te}$, or from CdTe powder, depending on the experiment, placed in the partially separated ampoule compartment to provide the annealing atmosphere. In addition, some CdTe samples were annealed in the sealed empty ampoule (without any additives). All ampoules were evacuated down to the pressure of $\sim 10^{-5}$ Torr, sealed and inserted into a horizontal, three- zone oven with a uniform temperature zone, significantly longer than the ampoule length, to ensure isothermal annealing conditions. To obtain more accurate data of the effect of annealing atmosphere on the electrical properties, some loaded ampoules, identical in size, but each with a different batch of crystals, were put in the oven simultaneously, side by side. After a certain annealing time at a fixed temperature, several of the ampoules were pulled out and quenched down to $0{ }^{\circ} \mathrm{C}$, while the rest were cooled down slowly to room temperature at a rate of $\sim 1{ }^{\circ} \mathrm{C} / \mathrm{min}$. The annealing time was varied between four and eight days, depending on the annealing temperature (see Table I). As an internal calibration, to each run we added an ampoule with $\mathrm{In}_{4} \mathrm{Te}_{3}$ in the partially separated compartment and measured the electrical characteristics of the resulting CdTe crystals, to make sure they matched the results found earlier. ${ }^{2}$

\section{RESULTS AND DISCUSSIONS}

Since all starting crystals have high resistivity, the initial assumption is that the electrically active native point defects are in equilibrium according to

$$
\mathbf{D} \approx \mathbf{A}
$$

where $\mathbf{A}$ represents the concentration of $\mathrm{Cd}$ vacancies $\left(V_{\mathrm{Cd}}\right)$, which act as the only known isolated point-defect acceptor in CdTe, ${ }^{13,14}$ and D corresponds to the donor density. Several point defects in CdTe function as donors. Thus, neglecting any complexes, the following relation can be written:

$$
\mathbf{D} \approx \mathbf{C d}_{i}+\mathbf{T e}_{\mathrm{Cd}}+\mathbf{V}_{\mathrm{Te}}+\mathbf{T} \mathbf{e}_{i},
$$

where $\mathrm{Cd}_{i}=$ interstitial $\mathrm{Cd}$; $\mathrm{Te}_{\mathrm{Cd}}=\mathrm{Te}$ on a $\mathrm{Cd}$ site (antisite); $V_{\mathrm{Te}}=\mathrm{Te}$ vacancy; $\mathrm{Te}_{i}=$ interstitial Te. The concentrations of these defects strongly depend on the thermal treatment. ${ }^{13,14}$ Deviation from stoichiometry (ideal 1:1 Cd:Te 
ratio) takes place via native defect reactions and the native defects themselves influence the electrical properties.

Before explaining our experimental results, summarized in Table I for the typical temperatures of 400 and $550{ }^{\circ} \mathrm{C}$, we recall that:

(1) Quenching of CdTe results not only in freezing in of the high temperature crystal composition, but also of the defect concentrations, present at the annealing temperatures. Thus, except for the normal temperature dependence of defect ionization, the electrical activity of the point defects is frozen in. This is so because, as a result of the quenching, the defects remain separated, and cannot react with each other.

(2) Slow cooling facilitates reactions between the point defects.

\section{A. Annealing with CdTe powder}

Because equilibrium $\mathrm{Cd}$ and $\mathrm{Te}$ vapor pressures are created by evaporation of constituents from the powder, this prevents, therefore, a change in overall crystal composition. Samples annealed at $400{ }^{\circ} \mathrm{C}$ remain compensated, something that is expressed in the very high resistivity of $\sim 5 \mathrm{M} \Omega \mathrm{cm}$ for the quenched and slowly cooled samples (Table I).

Hall measurements of the samples annealed at 450$550{ }^{\circ} \mathrm{C}$ (Table I) show $n$-type electrical conductivity. This can be understood if the CdTe lattice composition deviates from an ideal 1:1 ratio, in the Cd-rich (Te-poor) direction. In the absence of Te evaporation or $\mathrm{Cd}$ in-diffusion from an outside source we propose that this happens according to the following reaction:

$$
\mathbf{T e}_{\mathrm{Te}} \Leftrightarrow \mathbf{V}_{\mathrm{Te}}+\mathbf{T e}_{i},
$$

which, shifted to the right, leads to a deviation of the CdTe lattice stoichiometry from the ideal 1:1 ratio, in the Cd-rich direction. This is so because, as pointed out in Ref. 17, $\mathrm{Te}_{i}$, are point defects, rather than native lattice constituents. Thus, while the overall composition (element concentration in the material) remains unchanged (in the absence of evaporation or in-diffusion of constituents), a Te-poor lattice composition (element concentration in the nodes of crystallographic lattice, i.e., overall composition excluding point defect concentration) of CdTe is achieved via process (3). This process establishes the equilibrium majority carrier concentration at the annealing temperature, because both $V_{\mathrm{Te}}$ and $\mathrm{Te}_{i}$ are known as electrically active donors. ${ }^{13}$ These additional donors disturb equilibrium (1), and make the material $n$ type. Such a situation can take place only if CdTe has an asymmetric homogeneity region towards $\mathrm{Cd}$-rich compositions over the $450-550{ }^{\circ} \mathrm{C}$ temperature range. This means that over this range the Cd-solidus curve should deviate from the CdTe line of stoichiometry (in contrast to what is the case at $\left.400^{\circ} \mathrm{C}\right)$.

Careful analysis of the Cd-Te P-T-X (pressuretemperature-composition) phase equilibrium diagram ${ }^{18,19}$ is required to confirm the above hypothesis. No significant homogeneity region was revealed on the T-X projection of the CdTe diagram at $450-550^{\circ} \mathrm{C}$. Fig. 1 presents schematically this T-X projection near 50 at. \% Te concentration. For this projection there is only one experimental point at $\sim 550{ }^{\circ} \mathrm{C}$

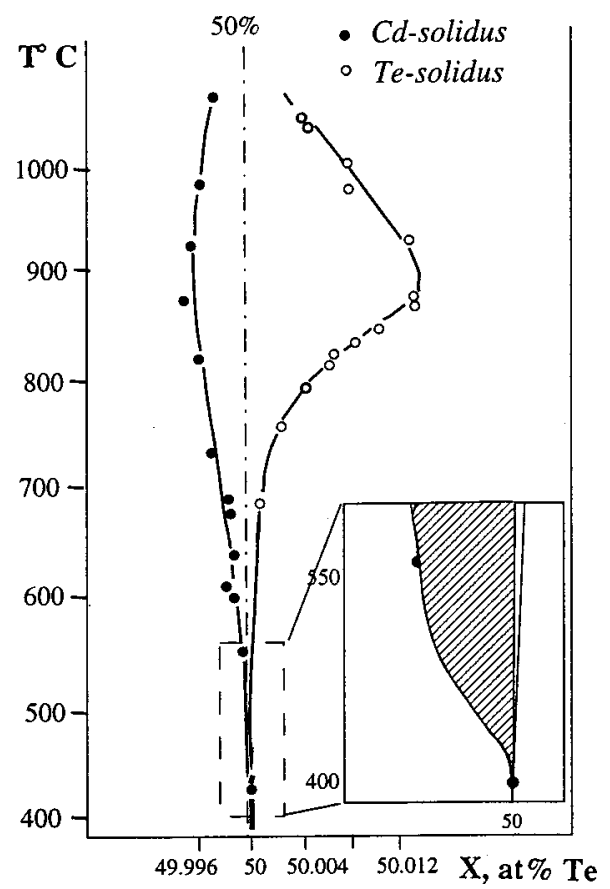

FIG. 1. T-X projection of the $\mathrm{Cd}-\mathrm{Te}$ phase diagram near CdTe stoichiometry $(50$ at. \% Te). Experimentally determined Cd solidus $(\bullet)$ and Te solidus (O) (after Refs. 18 and 19) and the assumed form of the CdTe solidus in the region of $400-550{ }^{\circ} \mathrm{C}$.

which is asymmetrical in the direction of $\mathrm{Cd}$ accumulation (Te depletion). Since it is difficult to show a Cd-solidus shift on the T-X projection, we constructed the isothermal $\mathrm{P}-\mathrm{X}$ sections (Fig. 2) at 400 and $550{ }^{\circ} \mathrm{C}$ (shaded area), presenting the two investigated temperatures. The method for calculation of the P-X sections is explained in Refs. 18 and 19. These sections reflect the equilibrium relations between the

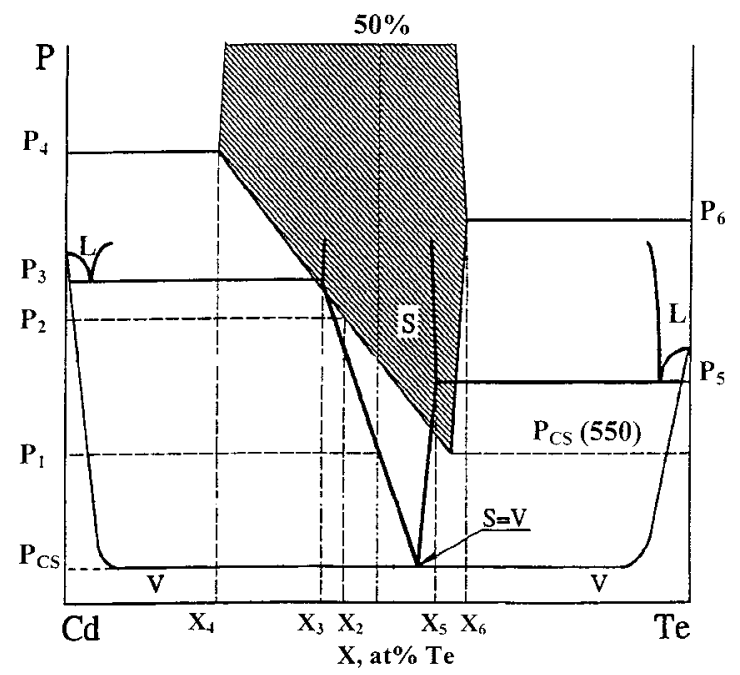

FIG. 2. Calculated isothermal sections of the Cd-Te P-T-X phase diagram at $400{ }^{\circ} \mathrm{C}$. The superimposed shaded area of the CdTe solidus volume corresponds to the $550{ }^{\circ} \mathrm{C}$ section. Representative, experimentally determined, vapor pressures are (in $\mathrm{mm} \mathrm{Hg}$ ): $\mathbf{P}_{\mathbf{1}}=3 \times 10^{-3}, \mathbf{P}_{\mathbf{2}}=0.31, \mathbf{P}_{\mathbf{3}}=1.23, \mathbf{P}_{\mathbf{4}}$ $=34.03, \mathbf{P}_{5}=0.06, \mathbf{P}_{\mathbf{6}}=2.28, \mathbf{P}_{\mathrm{cs}}=10^{-5}, \mathbf{P}_{\mathrm{cs}}(\mathbf{5 5 0})=4 \times 10^{-3} . \mathbf{X}_{\mathbf{n}}$ are the calculated equilibrium compositions (after Refs. 18 and 19). $\mathbf{S}=$ solid $\mathrm{CdTe} ; \mathbf{L}=$ liquid; $\mathbf{V}=$ vapor; "S=V:" congruent sublimation (cs) points. 

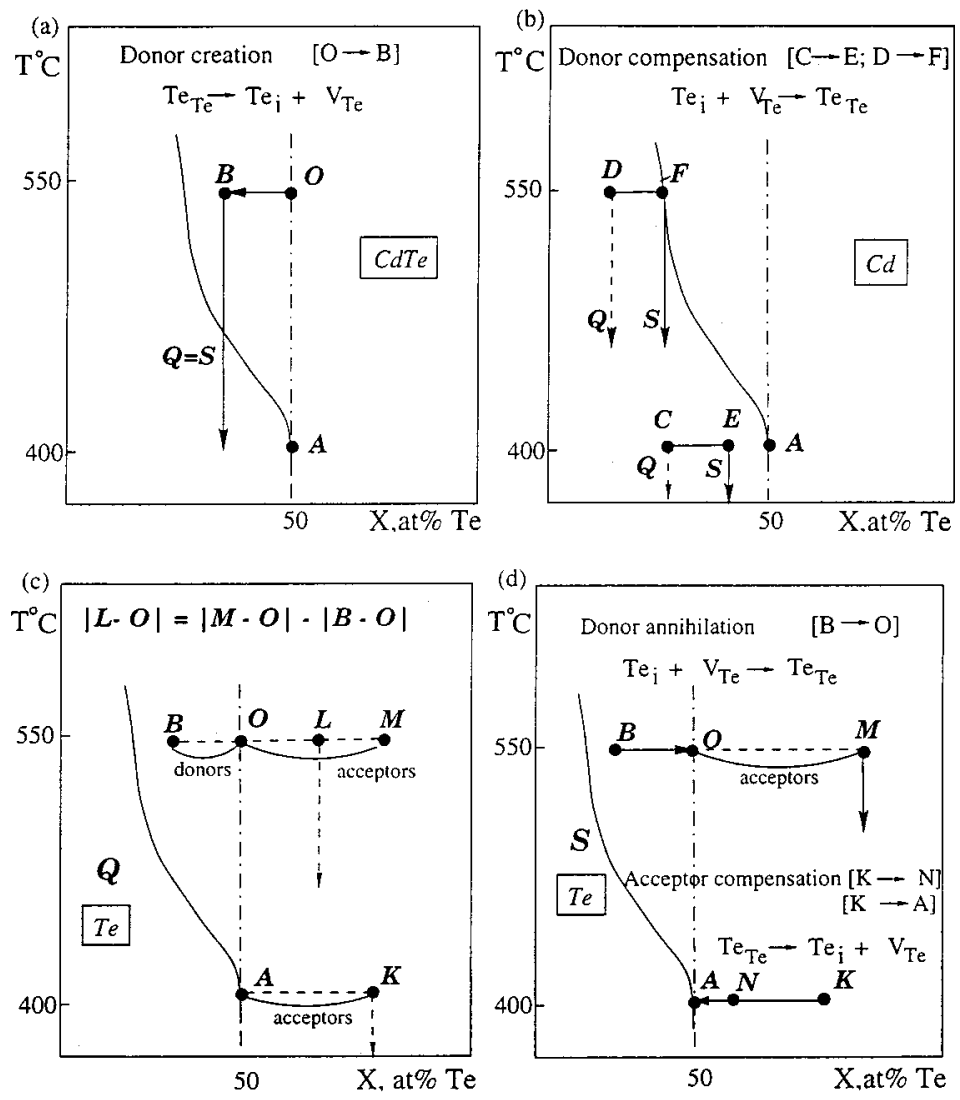

FIG. 3. Blow-ups of inset in Fig. 1, i.e., T-X projection of the $\mathrm{Cd}-\mathrm{Te}$ phase diagram near CdTe stoichiometry $(50$ at. $\% \mathrm{Te})$, to explain and illustrate the effects of different annealing conditions on the CdTe compositions. After annealing in (a) CdTe, (b) Cd and (c, d) Te atmospheres and subsequent Quenching or Slow cooling. point defect concentrations and annealing conditions (temperature and pressure).

The calculations that resulted in Fig. 2 showed that at $400{ }^{\circ} \mathrm{C}$ the vapor pressure of $\mathrm{CdTe}$ is very low $\left(P_{1}=3\right.$ $\times 10^{-3} \mathrm{~mm} \mathrm{Hg}$ ). Since the region of homogeneity is narrow, we assume that at this temperature there is no noticeable deviation from the 1:1 ratio in CdTe under these conditions.

Increase of the annealing temperature to $550{ }^{\circ} \mathrm{C}$ leads to an increase of the equilibrium vapor pressure to $P_{2}=0.31$ $\mathrm{mm} \mathrm{Hg}$ (Fig. 2), which, in turn, corresponds to the equilibrium composition $\mathrm{X}_{2}$ (Fig. 2) in the CdTe homogeneity region.

CdTe annealing, carried out between 450 and $550{ }^{\circ} \mathrm{C}$, is always accompanied by a shift (in Cd-rich direction) away from the CdTe line of stoichiometry towards the $\mathrm{Cd}$ solidus. This process takes place with the creation of additional donors according to reaction (3). The horizontal transition, corresponding to this reaction, is directed from point $\mathbf{O}$ to $\mathbf{B}$ in Fig. 3(a). Equilibrium composition $\left(\mathrm{X}_{2}\right)$ is a vertical projection on the horizontal (composition) axis. ${ }^{20}$ In other words, we end up with $n$-type material, rather than with the intrinsic material, obtained after annealing at $400{ }^{\circ} \mathrm{C}$ (point $\mathbf{A}$ in Fig. 3(a) and Table I).

Experiments carried out above $550{ }^{\circ} \mathrm{C}$ proved the validity of this model, based on reaction (3)..$^{21}$ At those temperatures $\left(>550{ }^{\circ} \mathrm{C}\right)$ the deviation from stoichiometry occurs in both directions, viz., -Te depletion and Te accumulation (Fig. 1). In the last case, reaction (3) is shifted to the left and we get annihilation while in the opposite direction we get creation of the $\mathrm{Te}_{i}$ and $V_{\mathrm{Te}}$ point defects. As a result, since the above-mentioned opposite reactions compensate each other, the CdTe crystals remain intrinsic regardless of the cooling regimes. This is in contrast to the situation, between $450-550^{\circ} \mathrm{C}$, unique for the $C d-T e$ system, when the reaction goes in only one direction, viz., Te depletion.

\section{B. Annealing in $\mathrm{Cd}$ atmosphere}

Heating in the presence of $\mathrm{Cd}$ results in $\mathrm{Cd}$-saturated vapor pressures $P_{3}=1.23 \mathrm{~mm} \mathrm{Hg}$ at $400{ }^{\circ} \mathrm{C}$ and $P_{4}=34.03$ $\mathrm{mm} \mathrm{Hg}$ at $550{ }^{\circ} \mathrm{C}$. These pressures correspond to the $\mathrm{Cd}$-rich equilibrium compositions $\mathrm{X}_{3}$ and $\mathrm{X}_{4}$ (see Fig. 2). No Te evaporation from the lattice takes place because of the low Te partial pressure at $350-550{ }^{\circ} \mathrm{C}\left(\sim 10^{-6} \mathrm{~mm} \mathrm{Hg}^{19}\right)$. The above-referenced equilibrium compositions $\mathrm{X}_{3}$ and $\mathrm{X}_{4}$ indicate the maximum possible equilibrium composition change.

$\mathrm{Cd}$ diffuses into the CdTe lattice due to its relatively high diffusion coefficient $\left(\sim 10^{-15}\right.$ and $3 \times 10^{-13} \mathrm{~cm}^{2} / \mathrm{s}$ at 400 and $550{ }^{\circ} \mathrm{C}$, respectively $\left.{ }^{22}\right)$. Therefore, additional $\mathrm{Cd}_{i}$ dopants may be introduced as a result of this diffusion, and $\mathrm{Cd}$ vacancies can be filled due to the reaction with interstitial $\mathrm{Cd}$. These processes decrease the concentration of $V_{\mathrm{Cd}}$ acceptors and increase the concentration of donors [see reaction (2)]. The material becomes, therefore, $n$-type. The overall crystal composition changes in both cases (400 and $\left.550{ }^{\circ} \mathrm{C}\right)$.

Let us consider first quenched CdTe, annealed at 400 and $550{ }^{\circ} \mathrm{C}$. From Table I, we see that the majority carrier concentration in $\mathrm{CdTe}$ crystals, quenched from $550{ }^{\circ} \mathrm{C}$, is slightly higher than the electron concentrations for samples quenched from $400^{\circ} \mathrm{C}\left(5 \times 10^{16} \mathrm{~cm}^{-3}\right.$ vs $\left.3.5 \times 10^{16} \mathrm{~cm}^{-3}\right)$. This difference in concentrations is partially related to the 
higher diffusion coefficient of $\mathrm{Cd}$ at higher temperatures. ${ }^{22}$ The main reason, however, is related to the region of $\mathrm{Cd}$ nonstoichiometry, existing at $450-550{ }^{\circ} \mathrm{C}$, that supplies the CdTe crystal with additional donors [reaction (3), shifted to the right], and this, in turn, leads to an increase of electron concentration [points $\mathbf{C}$ and $\mathbf{D}$ in Fig. 3(b) and Table I]. The vertical projections from points $\mathbf{C}$ and $\mathbf{D}$, denoted by $Q$, on the composition axis determine the $\mathrm{Cd} / \mathrm{Te}$ ratio obtained by quenching.

We discuss now the results obtained on CdTe samples slowly cooled down from 400 and $550{ }^{\circ} \mathrm{C}$. An increase in $\mathrm{Cd}$ sublattice constituent has to be accompanied by an adequate increase in $\mathrm{Te}_{\mathrm{Te}}$ concentration (i.e., lattice $\mathrm{Te}$ ) to reach equilibrium. This is expressed by the horizontal displacement in the Te-rich direction from the nonequilibrium to the equilibrium concentration, towards the $\mathrm{Cd}$-solidus curve, i.e., from points $\mathbf{C}$ to $\mathbf{E}$ and $\mathbf{D}$ to $\mathbf{F}$ at 400 and $550{ }^{\circ} \mathrm{C}$, respectively [Fig. 3(b)]. This process takes place according to reaction (3), shifted to the left in this case. The reaction between $V_{\mathrm{Te}}$ and $\mathrm{Te}_{i}$, under slow cooling condition, decreases the amount of donors in the system and leads, as a result, to partial compensation [points E, F in Fig. 3(b) and Table I]. During $\mathrm{Cd}$-atmosphere annealing at $550^{\circ} \mathrm{C}$ the system is at a certain composition $\mathbf{D}$ outside the CdTe homogeneity region, and subsequent slow cooling leads to the indicated composition change from point $\mathbf{D}$ to point $\mathbf{F}$ [Fig. 3(b)]. This is in contrast to slow cooling from $550{ }^{\circ} \mathrm{C}$ during annealing in CdTe atmosphere. In the last case the system remains in the CdTe homogeneity region and thus there is no change in composition during fast or slow cooling [point $\mathbf{B}$ in Fig. 3(a)]. That is why no difference in mobility and majority carrier concentrations is found for such CdTe annealed samples that were quenched or cooled slowly from $550^{\circ} \mathrm{C}$ (Table I).

\section{Annealing in Te atmosphere}

Annealing in $\mathrm{Te}$ atmosphere creates saturated vapor pressures of Te, $P_{5}=0.06 \mathrm{~mm} \mathrm{Hg}$ at $400{ }^{\circ} \mathrm{C}$ and $P_{6}=2.28$ $\mathrm{mm} \mathrm{Hg}$ at $550{ }^{\circ} \mathrm{C}$, which dictate the equilibrium compositions $\mathrm{X}_{5}$ and $\mathrm{X}_{6}$, respectively (see Fig. 2). On the one hand, the Te diffusion coefficient, which is much lower than the $\mathrm{Cd}$ one, ${ }^{22}$ prevents Te diffusion from its vapor into CdTe. On the other hand, evaporation of lattice $\mathrm{Cd}$ is possible and this leads to the nonequilibrium compositions at 400 and $550{ }^{\circ} \mathrm{C}$ annealing temperatures [points $\mathbf{K}$ and $\mathbf{M}$ in Fig. 3(c) and Table I]. Cd evaporation from the lattice increases $V_{\mathrm{Cd}}$ (acceptor) concentration, as compared to the equilibrium situation [Eq. (1)]. Such an increase, in turn, results in $p$-type conductivity with a hole concentration $\sim 1.5-2 \times 10^{16} \mathrm{~cm}^{-3}$ for crystals which were quenched following either 400 or $550^{\circ} \mathrm{C}$ annealing. We note that the majority carrier (hole) mobility for the quenched crystals, annealed at $550{ }^{\circ} \mathrm{C}$, is $\sim 20$ times lower than for crystals annealed at $400^{\circ} \mathrm{C}$ and then quenched. This difference is explained by carrier scattering on the additional point defects (donors) ${ }^{23}$ created at $550{ }^{\circ} \mathrm{C}$ according to reaction (3). In this case the concentration of majority holes $(\mathbf{L})$ is determined as total composition $(|\mathbf{O}-\mathbf{M}|)$ minus donor concentration $(|\mathbf{O}-\mathbf{B}|)$ [Fig. 3(c)].
During slow cooling from $400^{\circ} \mathrm{C}$, the system tends to compensate the shift to the Te-rich composition (due to $\mathrm{Cd}$ evaporation) by the creation of $V_{\mathrm{Te}}$ and $\mathrm{Te}_{i}$ (both act as donors) according to reaction (3). The additional acceptors $\left(V_{\mathrm{Cd}}\right)$ are compensated by the additional donors, and the CdTe crystals are highly resistive [point $\mathbf{A}$ in Fig. 3(d) and Table I].

Crystals, annealed at $550^{\circ} \mathrm{C}$, contain more $\mathrm{Cd}$ vacancies (acceptors), created due to evaporation of $\mathrm{Cd}$ from $\mathrm{CdTe}$ at higher temperature, than those annealed at $400{ }^{\circ} \mathrm{C}$. However, in parallel with acceptors, additional donors are created according to reaction (3) (point $\mathbf{B}$ in Figs. 3(c) and 3(d). For the slow cooling process, the opposite direction of reaction (3) leads to annihilation of the above-mentioned donors [point $\mathbf{O}$ in Fig. 3(d) and Table I]. The Cd vacancies (acceptors) determine, therefore, the $p$-type conductivity with high hole concentrations of $\sim 2 \times 10^{17} \mathrm{~cm}^{-3}$ [point $\mathbf{M}$ in Fig. 3(d) and Table I].

\section{Annealing in vacuum}

An equilibrium vapor pressure is created in the empty, sealed ampoule (without elemental $\mathrm{Cd}$, Te or CdTe powder) due to preferential $\mathrm{Cd}$ evaporation from the lattice. This leads to an increase of $V_{\mathrm{Cd}}$ (acceptor) concentration, similar to annealing in Te atmosphere (see above). The overall CdTe composition shifts to the Te-rich direction, something that leads to $p$-type conductivity. We note here the significant difference between annealing in vacuum and with $\mathrm{CdTe}$ powder. In the latter case, $\mathrm{Cd}$ evaporation from the single crystals is strongly suppressed due to Cd evaporation from the powder (effective surface area of CdTe powder is much larger that that of a CdTe single crystal).

$400^{\circ} \mathrm{C}$. Quenching results in $p$-type material with a hole concentration $\sim 10^{16} \mathrm{~cm}^{-3}$ [point $\mathbf{K}$ in Fig. 3(c) and Table I]. Slow cooling leads to partial compensation of acceptors $-V_{\mathrm{Cd}}$, similar to annealing in Te atmosphere [point $\mathbf{N}$ in Fig. 3(d) and Table I].

$550^{\circ} \boldsymbol{C}$. Two competitive processes exist for quenching. On the one hand, additional acceptors, $V_{\mathrm{Cd}}$, created due to $\mathrm{Cd}$ sublattice evaporation at that temperature, are frozen in. On the other hand, the presence of the Cd nonstoichiometry region results in donor $\left(V_{\mathrm{Te}}\right.$ and $\left.\mathrm{Te}_{i}\right)$ creation according to reaction (3). These donors compensate acceptors and, as a result, the composition ( $\sim 50$ at. \% Te) dictates a high resistivity of the crystals [point $\mathbf{O}$ in Fig. 3(c) and Table I].

For the slow cooling process the additional donors, created at high temperatures [cf. reaction (3)], annihilate, similar to what occurs during slow cooling in Te atmosphere, due to reaction (3) going to the left. The Cd vacancies (acceptors) determine the high hole concentration in the system [point $\mathbf{M}$ in Fig. 3(d) and Table I]. The highest possible hole concentration was $8.5 \times 10^{17} \mathrm{~cm}^{-3}$.

\section{CONCLUSIONS}

Shifting the balance between the native donors and acceptors, present in CdTe, can serve to modify the electrical properties of originally intrinsic single crystals of CdTe. The unique region of nonstoichiometry in this system, between 
450 and $550{ }^{\circ} \mathrm{C}$, which is shifted towards the Te-poor direction, allows control over the donor concentration in the system. This, in turn, allows control over the electrical properties of CdTe single crystals.

\section{ACKNOWLEDGMENTS}

The authors thank the Israel Ministry of Immigrant Absorption (to V.L.) and the German-Israel Foundation for Science, G.I.F. (to D.C.), for partial support and a reviewer for helpful comments. V.L. thanks Dr. Anna Pomyalov for fruitful discussions and indispensable help with the figures.

${ }^{1}$ E. D. Jones and J. C. Clark, in Properties of Narrow Gap Cadmium-Based Compounds, EMIS Datareviews Series, edited by P. Capper (INSPEC, IEE, London, 1994), p. 472.

${ }^{2}$ V. Lyahovitskaya, L. Kaplan, J. Goswami, and D. Cahen, J. Cryst. Growth 197, 106 (1999).

${ }^{3}$ A. A. Alnajjar, C. C. R. Watson, A. W. Brinkman, and K. Durose, J. Cryst. Growth 117, 385 (1992).

${ }^{4}$ M. G. Astles, in Ref. 1, p. 494

${ }^{5}$ T. Aramoto, S. Kumazawa, H. Higuchi, T. Arita, S. Shibutani, T. Nishio, J. Nakajima, M. Tsuji, A. Hanafusa, T. Hibino, K. Omura, H. Ohyama, and M. Murozono, Jpn. J. Appl. Phys., Part 1 36, 6304 (1997).

${ }^{6}$ Y. Marfaing, Rev. Phys. Appl. 12, 211 (1977).
${ }^{7}$ U. V. Desnica, Prog. Cryst. 36, 291 (1998).

${ }^{8}$ P. Capper, in Ref. 1 p. 489.

${ }^{9}$ R. Triboulet, A. Durant, P. Gall, J. Booafe, J. P. Fillard, and S. K. Krawczyk, J. Cryst. Growth 117, 227 (1992).

${ }^{10}$ R. Triboulet and Y. Marfaing, J. Cryst. Growth 51, 89 (1981).

${ }^{11}$ K. Yokota, S. Katayama, and T. Yoshikawa, Jpn. J. Appl. Phys., Part 121 , 456 (1982).

${ }^{12}$ M. Wienecke, H. Berger, and M. Schenk, Mater. Sci. Eng., B 16, 219 (1993); M. Wienecke, B. Reinhold, and S. Hermann, J. Cryst. Growth 204, 441 (1999).

${ }^{13}$ M. A. Berding, Appl. Phys. Lett. 74, 552 (1999).

${ }^{14}$ Q. Chen, M. Hillert, B. Sundman, W. A. Oates, S. G. Fries, and R. SchidFetzer, J. Electron. Mater. 27, 961 (1998).

${ }^{15}$ L. Kronik and Y. Shapira, Surf. Sci. Rep. 37, 1 (1999).

${ }^{16}$ K. Sholz, H. Stiens, and G. Müller-Vogt, J. Cryst. Growth 197, 586 (1999).

${ }^{17}$ J. C. Brice, Prog. Cryst. 13, 39 (1986).

${ }^{18}$ J. H. Greenberg, V. N. Guskov, V. B. Lazarev, and O. V. Shebershneva, Mater. Res. Bull. 27, 847 (1992); J. H. Greenberg, V. N. Guskov, V. B. Lazarev, and O. V. Shebershneva, J. Solid State Chem. 102, 382 (1993); J. H. Greenberg, J. Cryst. Growth 161, 1 (1996).

${ }^{19}$ J. H. Greenberg, J. Cryst. Growth 197, 406 (1999).

${ }^{20}$ P. Rudolph, Prog. Cryst. 29, 375 (1994).

${ }^{21}$ V. Lyahovitskaya et al. (unpublished).

${ }^{22}$ J. C. Clark and E. D. Jones, in Ref. 1 , p. 459.

${ }^{23}$ S. M. Sze, Semiconductor Devices: Physics and Technology (Wiley, New York, 1985). 